Wind Energ. Sci. Discuss., doi:10.5194/wes-2017-6, 2017

Manuscript under review for journal Wind Energ. Sci.

Discussion started: 13 February 2017

(c) Author(s) 2017. CC-BY 3.0 License.

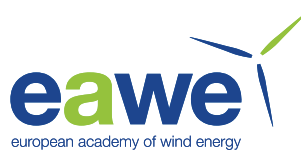

\title{
Full HAWT rotor CFD simulations using different RANS turbulence models compared with actuator disk and experimental measurements
}

\author{
Nikolaos Stergiannis ${ }^{1,2,3}$, Jeroen van Beeck ${ }^{2}$, and Mark C. Runacres ${ }^{1}$ \\ ${ }^{1}$ Vrije Universiteit Brussel, Faculty of Engineering, Thermo and Fluid Dynamics Research Group (FLOW), \\ Pleinlaan 2, B-1050, Brussels, Belgium \\ ${ }^{2}$ Von Karman Institute for Fluid Dynamics, Department of Environmental and Applied Fluid Dynamics, \\ Waterloosesteenweg 72, B-1640, Brussels, Belgium \\ ${ }^{3}$ 3E S.A., Kalkkaai 6, B-1000, Brussels, Belgium \\ Correspondence to: Nikolaos Stergiannis (nikolaos.stergiannis@vub.ac.be)
}

\begin{abstract}
.
The development of large-scale wind energy projects has created the demand for increasingly accurate and efficient models that limit a project's uncertainties and risk. Wake effects are of great importance and are relevant for the optimization of wind farms. Despite a growing body of research, there are still many open questions and challenges to overcome. In computational

5 modelling, there are always numerous input parameters such as material properties, geometry, boundary conditions, initial conditions, turbulence modelling etc. whose estimation is difficult and their values are often inaccurate or uncertain. Due to the lack of information of several sources, e.g., uncertainties present in operating conditions as well as in the mathematical modelling, the computational output is also uncertain. It is therefore very important to validate the mathematical models with experiments performed in controlled conditions. In the present paper, the single wake characteristics of a Horizontal-Axis Wind Turbine Rotor (HAWT) and their spatial evolution are investigated with different Computational Fluid Dynamics (CFD) modelling approaches and compared to experimental measurements.
\end{abstract}

The steady state 3-D Reynolds-Averaged Navier Stokes (RANS) equations are solved in the open-source platform OpenFOAM, using different turbulence closure schemes. For the full-rotor CFD simulations, the Multiple Reference Frames (MRF) approach was used to model the rotation of the blades. For the simplified cases, an actuator disk model was used with the experimentally measured thrust $\left(C_{T}\right)$ and power $\left(C_{P}\right)$ coefficient values. The performance of each modelling approach is compared with experimental wind tunnel wake measurements from the 4th blind test organized by NOWITECH and NORCOWE in 2015. Numerical results are compared with experimental data along three horizontal lines downstream, covering all the wake regions. Wake predictions are shown to be very sensitive to the choice of the RANS turbulence model. For most cases, the $\mathrm{ADM}$ under-predicts the velocity deficit, except for the case of $R N G k-\varepsilon$ which showed a superb performance in the mid and far wake. The full wind turbine rotor simulations showed good agreement to the experimental data, mainly in the near wake, amplifying the differences between the simplified models. 
Wind Energ. Sci. Discuss., doi:10.5194/wes-2017-6, 2017

Manuscript under review for journal Wind Energ. Sci.

Discussion started: 13 February 2017

(c) Author(s) 2017. CC-BY 3.0 License.

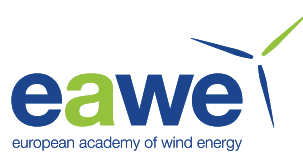

\section{Introduction}

During the lifetime of a wind farm, the operating wind turbines have to deal with multiple interactions. Part of the wind's kinetic energy is extracted by the rotors, resulting in a velocity deficit and increased levels of turbulence downstream (Vermeer et al., 2003). Wake effects can cause total annual power losses up to $30 \%$.

The wind turbines in a row are exposed to single or multiple upstream wake flows, resulting in power losses and additional loads from increased turbulence fluctuations (Rados et al., 2012; Prospathopoulos et al., 2011; Barthelmie et al., 2007; Larsen et al., 1996, 1998, 2003; Magnusson et al., 1996). To optimize a wind farm over a certain spatial area and reach the maximum potential production of the installed wind turbines, we have to understand the physics involved in the process of making torque from wind and be able to predict effectively the wake effects. The estimation of the wake characteristics helps the developers to optimize the final wind farm layout under the prevailing winds, ensuring improved power extraction and working conditions for the downstream wind turbine generators. Wake optimization can benefit the project's lifetime OPerational EXpenses (OPEX), since operating wind turbine generators are expected to be more reliable with less total failures (Larsen et al., 1998).

To predict wakes, several linear models have been developed and applied in industry (Jensen, 1983; Katic et al., 1986; Ainslie, 1988; Rados et al., 2002). However, despite their ease of use, all these models are based on simple assumptions and experimental observations. On the other hand, Computational Fluid Dynamics (CFD) simulations provide more sophisticated methods, such as the 3-dimensional solution of the Navier-Stokes equations, that represent the flow field with great accuracy (Mikkelsen, 2003). Although CFD simulations can be performed on both steady and unsteady state problems, it is common and acceptable to use, with certain limitations, the assumption of steady state approach to resolve a time-varying (unsteady state) problem when one is interested in the mean values of the flow. The numerical solution of the RANS equations using a twoequation turbulence closure model (Markatos, 1986; Wilcox, 1993) is a common approach with reasonable computational cost for industrial applications involving flows of high Reynolds numbers. Methods that are inherently unsteady, such as Detached Eddy Simulation (DES), Large Eddy Simulation (LES) and Direct Numerical Simulation (DNS) can be more accurate but the high computational cost makes them less suitable for use in industrial applications. However, following the technological growth, the computational cost is expected to decrease in years to come and the usage of CFD will be increasingly affordable for optimizing complex industrial applications.

\section{Mathematical model}

\subsection{Statement of the problem}

The physical problem under investigation is the flow over two identical wind turbines in a row under the controlled conditions of a wind tunnel. The current study focuses on predicting the single wake characteristics and development using different CFD modelling approaches. 
Wind Energ. Sci. Discuss., doi:10.5194/wes-2017-6, 2017

Manuscript under review for journal Wind Energ. Sci.

Discussion started: 13 February 2017

(c) Author(s) 2017. CC-BY 3.0 License.

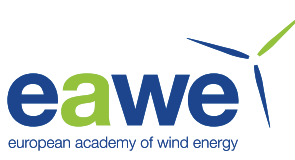

\subsection{Governing equations}

The governing equations solved of the flow field are the continuity and conservation of momentum equations:

$\frac{\partial \rho}{\partial t}+\nabla \cdot(\rho \boldsymbol{u})=0$

$5 \quad \frac{\partial(\rho \boldsymbol{u})}{\partial t}+\boldsymbol{u} \cdot \nabla(\rho \boldsymbol{u})=-\nabla p+\nabla \cdot \tau+\boldsymbol{S}_{\boldsymbol{M}}$

where $\rho$ is the air density, $\boldsymbol{u}$ is the fluid velocity vector, $p$ the pressure, $\tau$ the shear stress tensor and $\boldsymbol{S}_{M}$ a momentum source term. The stress tensor is related to the strain rate as:

$\tau=\mu\left[\nabla \boldsymbol{u}+(\nabla \boldsymbol{u})^{\mathrm{T}}-\frac{2}{3} \cdot \delta \cdot \nabla \boldsymbol{u}\right]=0$

where $\delta$ is Kronecker's delta and $\mu$ is the dynamic viscosity of the fluid.

\subsection{The Multiple Reference Frame (MRF) formulation}

The multiple reference frame (MRF) approach was used to model the internal rotating frames in a stationary computational mesh and reference frame. The velocities in the inertial and rotating reference frames, using the notation I for inertial and $\mathrm{R}$ for rotating, are related by:

$\boldsymbol{u}_{\mathrm{I}}=\boldsymbol{u}_{\mathrm{R}}+\boldsymbol{\Omega} \times \boldsymbol{r}$

15 The acceleration is expressed as:

$\left[\frac{d \boldsymbol{u}_{\mathrm{I}}}{d t}\right]_{\mathrm{I}}=\left[\frac{d \boldsymbol{u}_{\mathrm{R}}}{d t}\right]_{\mathrm{R}}+\frac{d \boldsymbol{\Omega}}{d t} \times \boldsymbol{r}+2 \boldsymbol{\Omega} \times \boldsymbol{u}_{\mathrm{R}}+\boldsymbol{\Omega} \times \boldsymbol{\Omega} \times \boldsymbol{r}$

The incompressible RANS equations for steady flow in the rotating frame of reference can be written in terms of relative velocity:

$\nabla \cdot \boldsymbol{u}_{\mathrm{R}}=0$

$20 \nabla \cdot\left(\boldsymbol{u}_{\mathrm{R}} \otimes \boldsymbol{u}_{\mathrm{R}}\right)+2 \boldsymbol{\Omega} \times \boldsymbol{u}_{\mathrm{R}}+\boldsymbol{\Omega} \times \boldsymbol{\Omega} \times \boldsymbol{r}=-\nabla\left(\frac{p}{\rho}\right)+\nu \nabla \cdot \nabla\left(\boldsymbol{u}_{\mathrm{R}}\right)$

\subsection{Turbulence modelling}

Two-equation turbulence models have been widely tested over the years and have been proven as an accepted compromise between accuracy and computational cost. In the present work, the performance of several two-equation turbulence models on wake expansion is tested and compared with measurements.

\subsubsection{Standard $k-\varepsilon$}

The standard $k-\varepsilon$ turbulence model (Launder and Spalding, 1974) is based on transport equations for the turbulence kinetic energy, $k$ and its dissipation rate, $\varepsilon$. The model parameters used are given in Table 1, following Launder et al (Launder et al., 1973). 
Wind Energ. Sci. Discuss., doi:10.5194/wes-2017-6, 2017

Manuscript under review for journal Wind Energ. Sci.

Discussion started: 13 February 2017

(c) Author(s) 2017. CC-BY 3.0 License.

(c) (i)

Table 1. Constants of the standard $k-\varepsilon$ turbulence model

\begin{tabular}{ccccc}
\hline$C_{\mu}$ & $C_{1}$ & $C_{2}$ & $\sigma_{k}$ & $\sigma_{\varepsilon}$ \\
0.09 & 1.44 & 1.92 & 1.0 & 1.3 \\
\hline
\end{tabular}

\subsubsection{Realizable $k-\varepsilon$}

In the realizable $k$ - $\varepsilon$ turbulence model of Tsan-Hsing Shih et al, a modified model dissipation rate equation and realizable 5 eddy viscosity formulation is used. A detailed description of the turbulence model is given in (Shih et al., 1995). The model constants are given in Table 2 .

Table 2. Constants of the realizable $k-\varepsilon$ turbulence model

\begin{tabular}{ccccc}
\hline$C_{\mu}$ & $A_{0}$ & $C_{2}$ & $\sigma_{k}$ & $\sigma_{\varepsilon}$ \\
0.09 & 4.0 & 1.9 & 1.0 & 1.3 \\
\hline
\end{tabular}

\subsubsection{RNG $k-\varepsilon$}

The $R N G k-\varepsilon$ turbulence model was developed by Yakhot et al (Yakhot et al., 1992) using the Re-Normalisation Group (RNG) methods in the Navier-Stokes equations in order to account for smaller scales of turbulence. The main difference and advantage compared to the standard $k-\varepsilon$ turbulence model, is that the model attempts to account for the different scales of motion through a modified epsilon equation, instead of determining the eddy viscosity from a single turbulence length scale. The model constants are given in Table 3.

Table 3. Constants of the $R N G k-\varepsilon$ turbulence model

\begin{tabular}{ccccccc}
\hline$C_{\mu}$ & $C_{1}$ & $C_{2}$ & $\sigma_{k}$ & $\sigma_{\varepsilon}$ & $\eta_{0}$ & $\beta$ \\
0.0845 & 1.42 & 1.68 & 0.71942 & 0.71942 & 4.38 & 0.012 \\
\hline
\end{tabular}

\subsubsection{Wilcox (1988) $k-\omega$}

The $k$ - $\omega$ turbulence model is a two-equation turbulence model that uses the turbulence kinetic energy $k$ and the specific rate of dissipation $\omega$ to predict turbulence. The model has been improved over the years with several versions and modifications (Wilcox, 1993, 2008), but in our cases we are using the Wilcox (1988) version (Wilcox, 1988) that is implemented in OpenFOAM ((OpenFOAM, 2016)). The model constants are given in Table 4. 
Wind Energ. Sci. Discuss., doi:10.5194/wes-2017-6, 2017

Manuscript under review for journal Wind Energ. Sci.

Discussion started: 13 February 2017

(c) Author(s) 2017. CC-BY 3.0 License.

Table 4. Constants of the standard $k-\omega$ turbulence model

\begin{tabular}{cccccc}
\hline$C_{\mu}$ & $\sigma_{k}$ & $\sigma_{\omega}$ & $\beta^{*}$ & $\beta$ & $\gamma$ \\
0.09 & 0.5 & 0.5 & 0.09 & 0.072 & 0.52 \\
\hline
\end{tabular}

\subsubsection{Menter (2003) $k-\omega S S T$}

The $k-\omega$ SST turbulence model, also known as Menter's Shear Stress Transport turbulence model, was introduced in 1994 by 5 F.R. Menter (Menter, 1994). It is a two-equation turbulence model that uses $k-\omega$ in the inner region of the boundary layer and switches to $k-\varepsilon$ in the free shear flow to improve the predictions of adverse pressure gradients. The model also has other modified versions (Hellsten, 1998). The updated model of 2003 (Menter et al., 2003) with a different expression to derive the eddy viscosity was used. The model constants are given in Table 5 .

Table 5. Constants of $k-\omega S S T$ turbulence model

\begin{tabular}{cccccccccc}
\hline$\sigma_{k 1}$ & $\sigma_{k 2}$ & $\sigma_{\omega 1}$ & $\sigma_{\omega 2}$ & $\beta^{*}$ & $\beta_{1}$ & $\beta_{2}$ & $\gamma_{1}$ & $\gamma_{2}$ & $\alpha_{1}$ \\
0.85 & 1.0 & 0.5 & 0.856 & 0.09 & 0.075 & 0.0828 & $5 / 9$ & 0.44 & 0.31 \\
\hline
\end{tabular}

\subsection{Wind turbine modelling}

In the case of actuator disk model, wind turbine rotors are approximated as momentum sinks (see eq. 2) to represent the axial thrust force $T$, associated with a constant uniform thrust coefficient $C_{T}$ over the rotor area:

$T=0.5 \rho C_{T} A U_{\text {ref }}^{2}$

where $A$ is the surface area of the rotor-disk, $\rho$ the air density, $U_{\text {ref }}$ the undisturbed reference free-stream velocity and $C_{T}$ the thrust coefficient of the rotor.

Once the $U_{\text {ref }}$ is known, $C_{T}$ can be estimated through the thrust curve of the wind turbine generator considered as uniform over the rotor area (Rados et al., 2012; Crasto et al., 2012; Mikkelsen, 2003). However, in operating conditions, the flow across the rotor is very complex with varying span-wise properties, due to the blade characteristics, rotational velocity, turbulence, finite number of blades and also other flow characteristics related to non-uniform inflow conditions, atmospheric boundary layer shear and so on.

To overcome the limitations of the standard actuator disk model, several more advanced models like the generalized actuator disk, actuator line model, actuator surface, have been proposed (Mikkelsen, 2003). The drawback of the advanced models is mainly that they need several input variables such as airfoil data, detailed blade geometry which most of the times are not available or confidential for industrial applications. Finally, most of the advance models require time resolved CFD simulations which increase the final computational cost (Sanderse et al., 2011). 
Wind Energ. Sci. Discuss., doi:10.5194/wes-2017-6, 2017

Manuscript under review for journal Wind Energ. Sci.

Discussion started: 13 February 2017

(c) Author(s) 2017. CC-BY 3.0 License.

The standard actuator disk model that was used in this study is implemented in OpenFOAM based on the axial induction 5 factor $a$ :

$a=1-\frac{C_{P}}{C_{T}}$

where $C_{P}$ is the power coefficient. The thrust force can then be expressed as:

$T=2 \rho A a(1-a) U_{\text {ref }}^{2}$

For all the cases under investigation, a constant uniform reference wind speed of $11.5 \mathrm{~m} / \mathrm{s}$ has been used. The coefficients $C_{P}$ and $C_{T}$ have been provided from the wind tunnel measurements and were used as inputs to the simplified models.

\section{The 4th blind test experiment}

The 4th Blind Test (BT4) experiment was organized by NOWITECH and NORCOWE in 2015. The total power output from two in-line turbines was investigated under the influence of different inlet conditions and turbine separation distance (Sætran and Bartl, 2015).

The axial separation distance between the turbines was set to $x / D=2.77, x / D=5.18$ and $x / D=9.00$, where the diameter $D=0.894 \mathrm{~m}$. Furthermore, three different inflow conditions at the inlet of the test section were tested:

- Low-turbulence uniform inflow (CASE-A): No grid at the inlet to the test section. At the position of the upstream turbine the turbulence intensity measured was $T I=0.23 \%$. The mean wind speed was uniform across the test section, apart from small wall boundary layer effects.

- High-turbulence uniform inflow (CASE-B): An evenly spaced grid at the tunnel inlet generated a higher turbulence intensity level of $T I=10.0 \%$ at the location of the upstream turbine. The mean wind speed was uniform across the test section.

- High-turbulence shear inflow (CASE-C): A turbulence grid with increasing vertical distance between the horizontal bars was installed at the inlet of the test section, creating a non-uniform shear flow with a mean turbulence intensity of $T I=10.0 \%$ over the rotor swept area of the upstream turbine.

At the experiment, the high turbulence intensity CASE-B was tested on three different downstream axial separation distances. In our study, the CASE-B3 of high TI and with axial separation distance of $x / D=9.00$ was chosen, mainly because more measured data were available downstream and additionally to eliminate the impact of the second wind turbine on the single wake expansion of the first turbine. For the simulations, a uniform inlet velocity profile of $11.5 \mathrm{~m} / \mathrm{s}$ was considered, similar to the inlet velocity profile of the wind tunnel. The two wind turbines are identical and constructed with the same aluminium blades, using the NREL S826 airfoil section from root to tip. 
Wind Energ. Sci. Discuss., doi:10.5194/wes-2017-6, 2017

Manuscript under review for journal Wind Energ. Sci.

Discussion started: 13 February 2017

(c) Author(s) 2017. CC-BY 3.0 License.

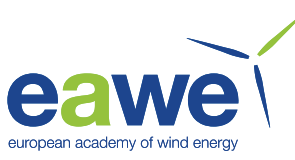

\section{Full rotor CFD simulations}

To address the question of how much information is lost with the simplified models, results are compared with more advanced CFD simulations that include the full wind turbine rotor geometries and their hubs.

\subsection{Computational domain}

The computational domains were designed to match the exact wind tunnel dimensions to represent the experimental setup and account for possible blockage effects (Fig. 1). Particularly for the CASE-B3, the domain have been extended by $3.7 \mathrm{~m}$ in length ( $30 \%$ of total) to avoid any numerical oscillations from the outlet at the far wake measurements downstream.

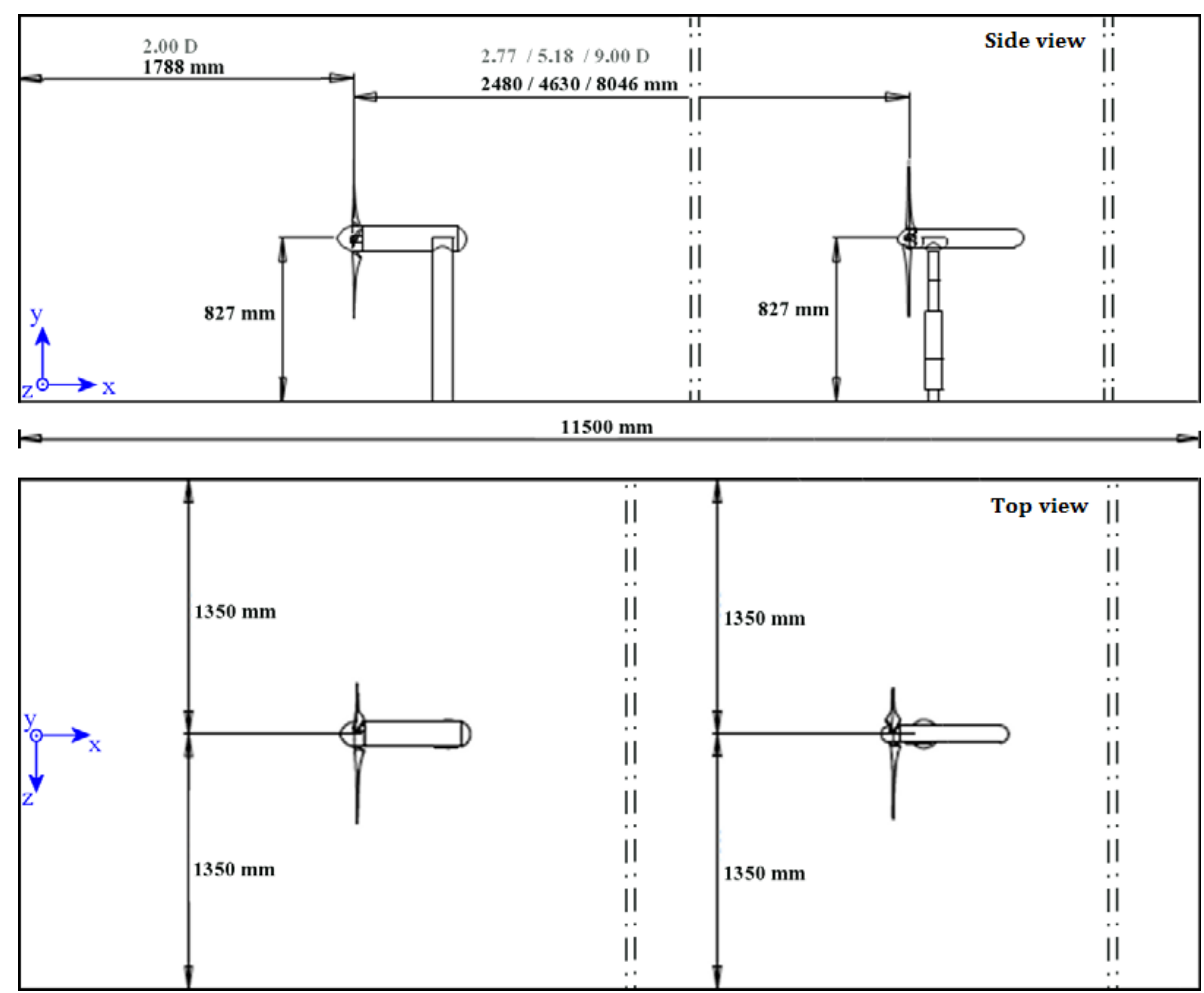

Figure 1. Wind tunnel dimensions and wind turbine positioning at the reference coordinate system. Sætran and Bartl (2015)

The blockMesh utility of OpenFOAM platform was used to generate a multi-block hexahedral computational mesh of $670 \mathrm{k}$ cells. That mesh was further modified and refined in regions of interest with the snappyHexMesh utility. Different refinements have been tested in the rotor-wake region with the actuator disk models using the $k$ - $\varepsilon$ turbulence model, to achieve a mesh independent solution. The hexahedral mesh elements of the background mesh (M1 $=0.67 \mathrm{Mi}$ cells) were doubled at each coordinate on every new level of refinement. The final computational meshes that have been generated and tested are given in Table 6. Steady state solutions using RANS and second order schemes, converged with residuals below $10^{-4}$. The 
Wind Energ. Sci. Discuss., doi:10.5194/wes-2017-6, 2017

Manuscript under review for journal Wind Energ. Sci.

Discussion started: 13 February 2017

(c) Author(s) 2017. CC-BY 3.0 License.

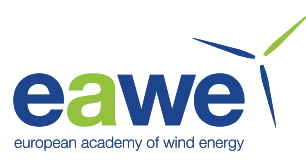

5 axial velocity over the line $\mathrm{L} 1=2.77 \mathrm{D}$ at the near wake was used as reference. The maximum error between the M3 (fine) and M4 (very fine) computational meshes was observed at the rotor center position $(z=0)$, where the velocity deficit of the single wake had a relative difference of $0.025 \mathrm{~m} / \mathrm{s}$. Therefore, the M3 (fine) mesh with two internal regions using two levels of refinement, proved to be a good compromise of accuracy and computational cost, and was chosen for all the CFD simulations.

Table 6. Size of the tested computational meshes in millions $\left(\times 10^{6}\right)$

\begin{tabular}{cccc}
\hline M1 & M2 & M3 & M4 \\
0.67 & 2.91 & 11.9 & 92.6 \\
\hline
\end{tabular}

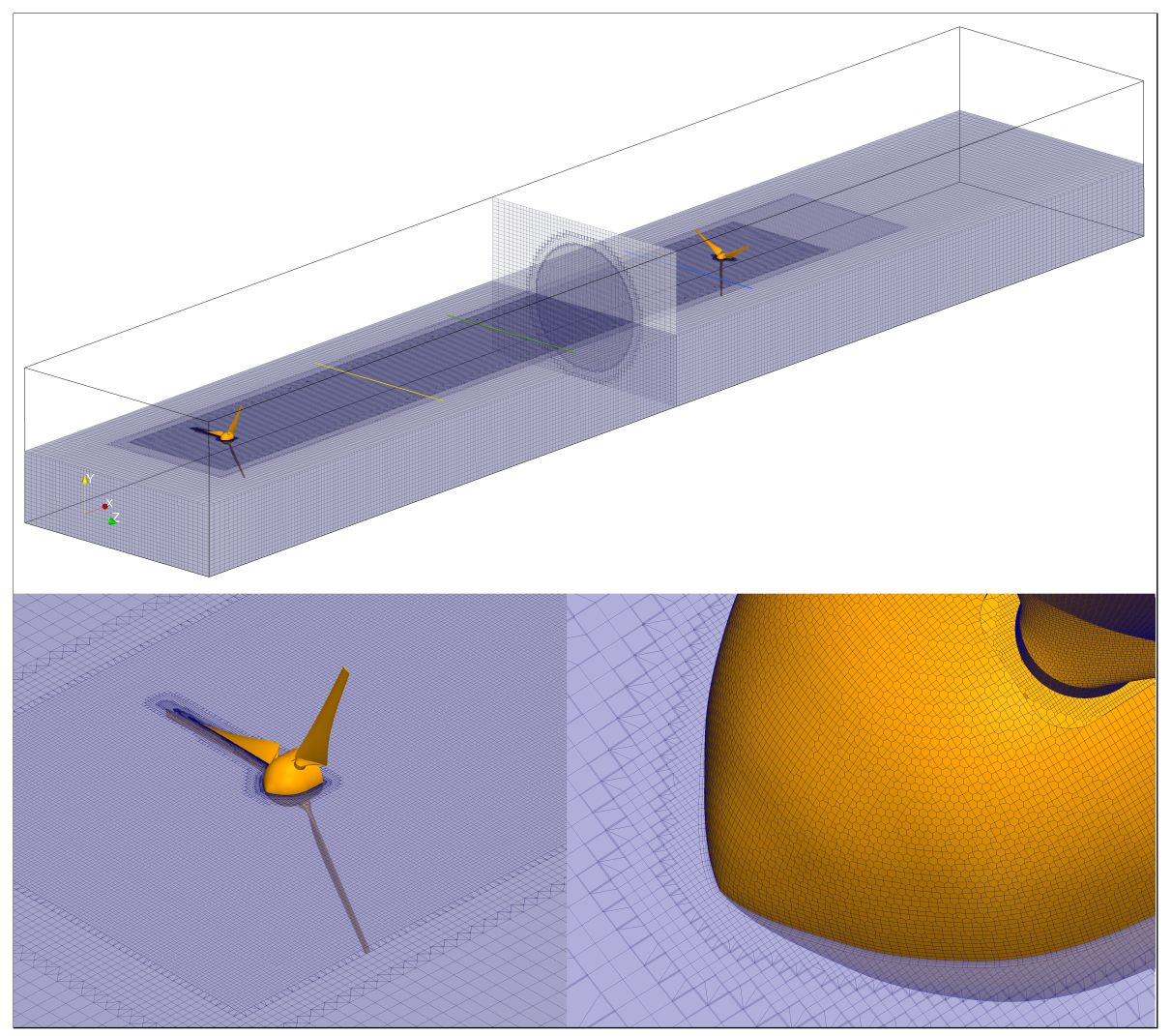

Figure 2. The fine mesh (M3) that was used for the CFD simulations. Top: details of the multi-block mesh and refinements that were generated with blockMesh and snappyHexMesh utilities. The three horizontal lines represent the measurements at the hub height $h_{\text {hub }}=0.827 \mathrm{~m}$ over the $\mathrm{L} 1$ (yellow) $=2.77 \mathrm{D}, \mathrm{L} 2$ (green) $=5.18 \mathrm{D}$ and L3 (blue) $=8.5 \mathrm{D}$ lines downstream of the first rotor. bottom-left: rotor-wake region using a refinement of level 2. bottom-right: surface cells and surface layers close to the geometry.

For the full-rotor cases, before the snapping of the mesh to the surfaces, several local refinements have been done also at the blades (level 6) and the hubs (level 5) of the wind turbines. Between all the refinement levels, four cells have been used to 
Wind Energ. Sci. Discuss., doi:10.5194/wes-2017-6, 2017

Manuscript under review for journal Wind Energ. Sci.

Discussion started: 13 February 2017

(c) Author(s) 2017. CC-BY 3.0 License.

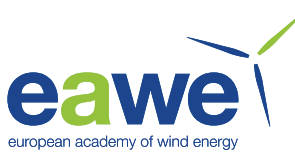

ensure a smooth transition. (Fig. 2, bottom-left). Four cell-layers were also added normal to the surfaces of the geometries with an expansion ratio of 1.5 (Fig. 2, bottom-right) to ensure a global average $y^{+}$value smaller than 50 . The global cell size at the centered block of the mesh was $0.0675 \mathrm{~m}^{3}$. According to each refinement level, those cells have been refined to $0.016875 \mathrm{~m}^{3}$ (level 1) and $0.003375 \mathrm{~m}^{3}$ (level 2), whereas the cells close to the geometries had a global size of $0.00105 \mathrm{~m}^{3}$ (level 5) at the hub and $0.0007 \mathrm{~m}^{3}$ (level 6) at the surface of the blades. The final fine computational mesh size was approximately 30Mi cells for the full-rotor CFD simulations and 14Mi cells for the ADM cases.

At the design condition for a Tip Speed Ratio (TSR) $\lambda=\Omega R / U_{\text {ref }}=6$, the Reynolds number at the tip is $R e_{c}=\lambda U c_{\text {tip }} / \nu \approx$ $10^{5}$, where $c_{\text {tip }}$ the chord length at the tip and $\nu$ the kinematic viscosity of air. Therefore the above cell sizes ensure that highReynolds wall functions can be applied at the first cell to the walls.

\subsection{Solution methodology and boundary conditions}

15 All the simulations have been performed in the open-source CFD platform OpenFOAM, using the steady state incompressible solver simpleFoam which is based on the Semi-Implicit Method for Pressure-Linked Equations (SIMPLE) algorithm (Patankar and Spalding, 1972).

Initial values and inlet values for the turbulence characteristics were estimated by using the experimental measured $T I$ and the turbulent length scales $\ell$ of each case with the following expressions:

$20 \quad k=\frac{3}{2}(\bar{U} T I)^{2}$

$\varepsilon=C_{\mu}^{0.75} \frac{k^{1.5}}{\ell}$

$\omega=C_{\mu}^{-0.25} \frac{\sqrt{k}}{\ell}$

where $\bar{U}=U_{\text {ref }}=11.5 \mathrm{~m} / \mathrm{s}$ and the density of air $\rho=1.25 \mathrm{~kg} / \mathrm{m}^{3}$. The boundary conditions that were used are summarized in Tables 7 and 8.

Table 7. Inflow and outflow boundary conditions

\begin{tabular}{ccc}
\hline & $\begin{array}{c}\text { Dirichlet } \\
\text { Fixed value }\end{array}$ & $\begin{array}{c}\text { von Neumann } \\
\text { Zero gradient }\end{array}$ \\
\hline Inlet & $\boldsymbol{u}, k, \varepsilon, \omega$ & $p$ \\
Outlet & $p=0$ & $\boldsymbol{u}, k, \varepsilon, \omega$ \\
\hline
\end{tabular}

\section{Results and discussion}

Results of the wake expansion for all the cases are presented below. Two CFD modelling approaches (full-rotor and actuator disk) have been tested using incompressible, steady state RANS and several turbulence models. All the cases converged after 
Wind Energ. Sci. Discuss., doi:10.5194/wes-2017-6, 2017

Manuscript under review for journal Wind Energ. Sci.

Discussion started: 13 February 2017

(c) Author(s) 2017. CC-BY 3.0 License.

Table 8. Other boundary conditions

\begin{tabular}{cc}
\hline Sides, top and bottom & Slip condition \\
Blades, hubs & Wall functions \\
Actuator discs & Momentum sinks \\
Rotating frame WT1 & TSR: $\lambda=6$ \\
Rotating frame WT2 & TSR: $\lambda=4-5$ \\
\hline
\end{tabular}

5 approximately 6000 iterations and were run for 10000 iteration. Pressure residuals converged below $10^{-3}$, velocity components below $10^{-5}$ and turbulence variables below $10^{-6}$. Bounded second-order numerical schemes were used for all the quantities, except for $k, \varepsilon$ and $\omega$ in which a blended first-second order numerical scheme was chosen for numerical stability. Results in all wake regions show that both CFD approaches are very sensitive to the choice of turbulence model.

Full-rotor simulations are capable to represent the flow field close to the wind turbine (Fig. 3), but they are over-estimate the velocity deficit at the far wake (Fig. 9).

The actuator disk model under-estimates the velocity deficit in most cases, except for the $k-\varepsilon R N G$ turbulence model 5 which shows excellent performance at the mid and far wake (Fig. 8).

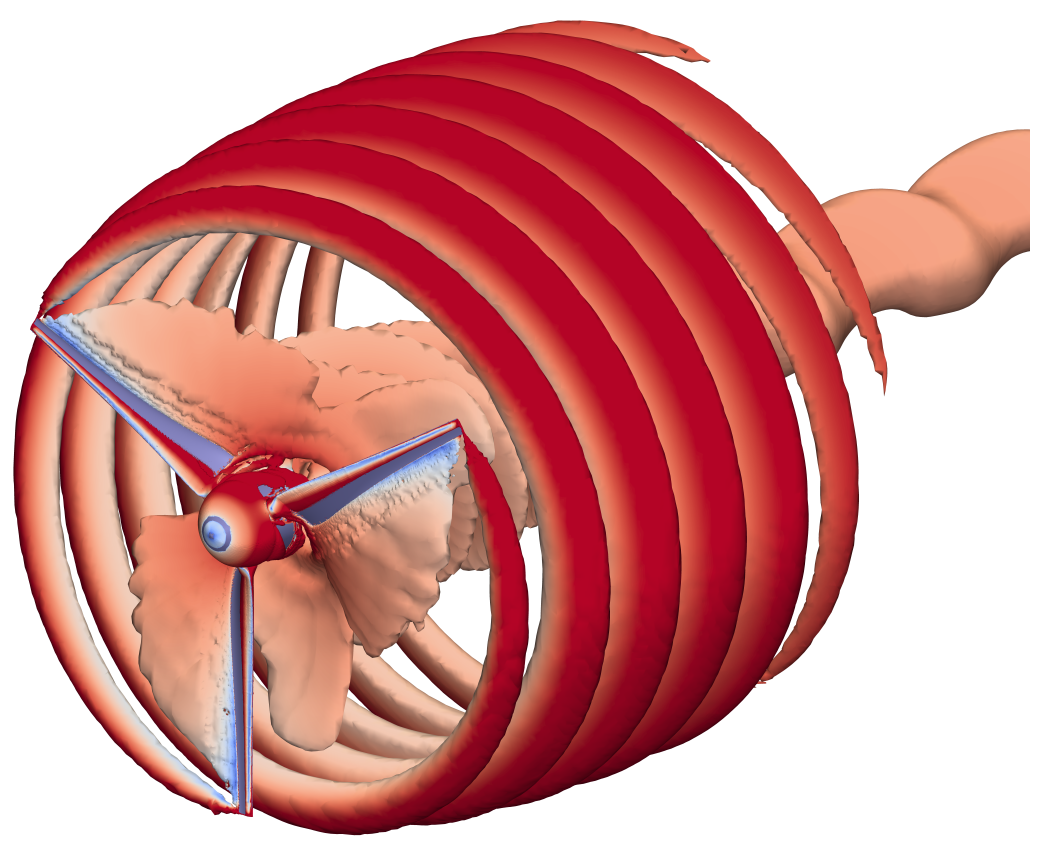

Figure 3. Iso-surfaces of the Q criterion colored by velocity for the case of full-rotor CFD simulation, using RANS and the $k-\omega$ turbulence model 
Wind Energ. Sci. Discuss., doi:10.5194/wes-2017-6, 2017

Manuscript under review for journal Wind Energ. Sci.

Discussion started: 13 February 2017

(c) Author(s) 2017. CC-BY 3.0 License.

\subsection{Predictions of axial velocity, turbulence kinetic energy (TKE), and vorticity}

In order to compare and study the differences between the simplified ADM and the full-rotor CFD simulations, contours of the velocity, turbulence kinetic energy and of vorticity at the xy-plane and at the hub height $\left(h_{\text {hub }}=0.827 \mathrm{~m}\right)$ are given for all the turbulence models.

The actuator disk model is more sensitive to the different turbulence models compared to the full-rotor simulations. Results of the ADM confirm that it is implemented correctly, since it represents a uniform momentum sink, as observed in Figures 5a, 6a and 7a. The iso-surfaces of the Q criterion (Fig. 4), are in agreement with the contours of vorticity (Fig. 7a) in which the strong effect of the shear stresses at the edge of the disk area is apparent. Results of TKE (Fig. 6a) for the ADM case show that the $k-\omega$ and the $k-\omega S S T$ turbulence models are less sensitive to the shear stresses caused by the free stream flow at the disk circumference, in contrast with the group of $k-\varepsilon$ turbulence models. Instead, we observe that there is enhanced turbulence production at the recirculation zone, behind the disk, where a pressure drop is also present. The wakes of the modified $k-\varepsilon$ turbulence models produce more TKE and vorticity at the blades-tip positions. Additionally, from the contours of turbulence (Fig. 6a) and of velocity (Fig. 5a) we can conclude that there is a strong connection between the production of turbulence and the wake recovery. Especially for the case of the $k-\omega$ turbulence model, the increased level of turbulence production causes a faster velocity recovery at the mid and far wake. The physical explanation for this phenomenon is that the increased turbulence will cause a strong interaction and mixing of the wake with the free stream lateral flow. We conclude that for the case of the $\mathrm{ADM}$, a choice from the $k-\varepsilon$ turbulence models group is recommended.

The full-rotor simulations show large wake development downstream of the first wind turbine with all the turbulence models (Fig. 5b). That behaviour is related to the severe under-estimation of the turbulence intensity (Fig. 6b). Preliminary tests showed that the small turbulence production downstream is also related to the absence of nacelles and towers. The TKE production in the wake of the second wind turbine is greater at the blade-tip positions downstream compared to the single wake predictions of the first. We can observe that the surrounding turbulence at the position of the second wind turbine is

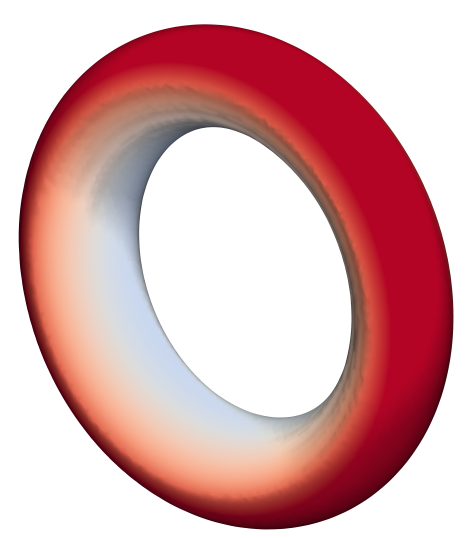

Figure 4. Iso-surfaces of the Q criterion colored by velocity for the case of actuator disk model, using RANS and the $k-\omega$ turbulence model 
Wind Energ. Sci. Discuss., doi:10.5194/wes-2017-6, 2017

Manuscript under review for journal Wind Energ. Sci.

Discussion started: 13 February 2017

(c) Author(s) 2017. CC-BY 3.0 License.

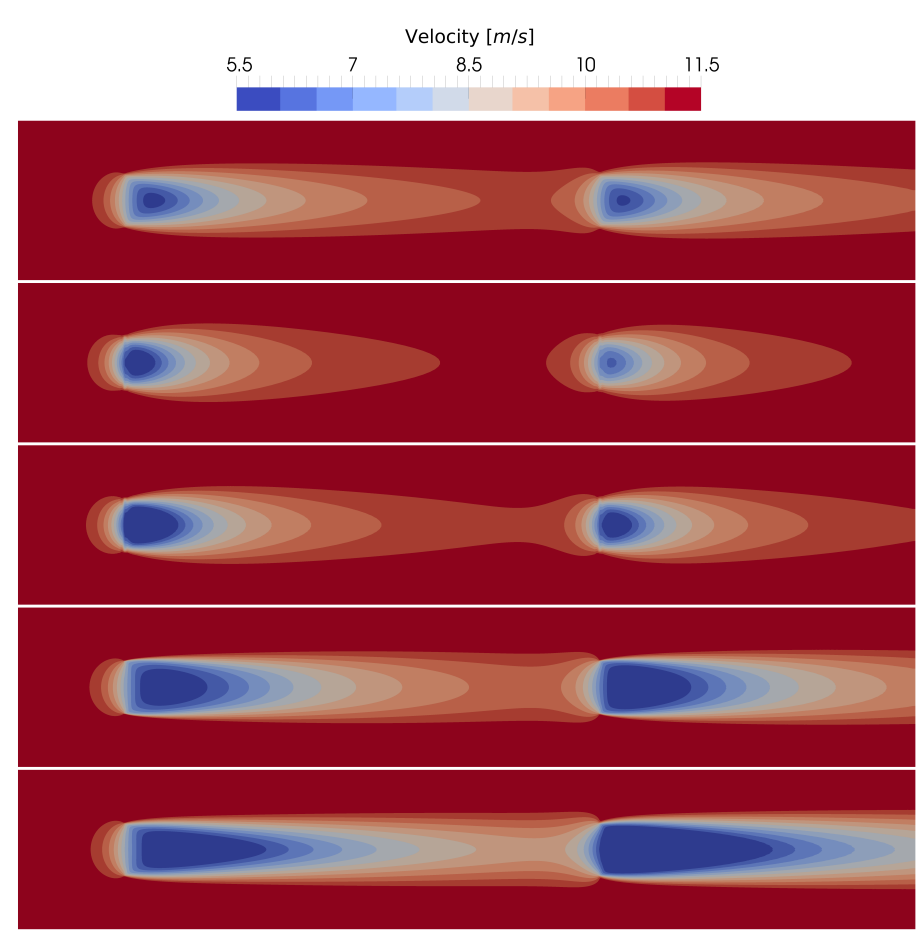

(a)

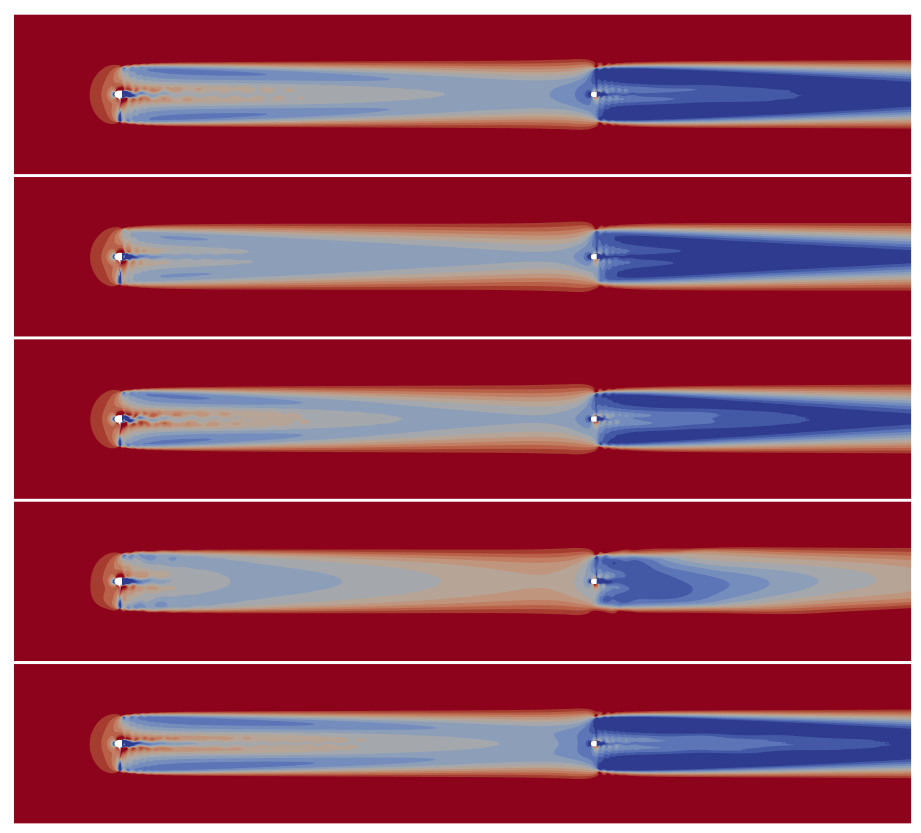

(b)

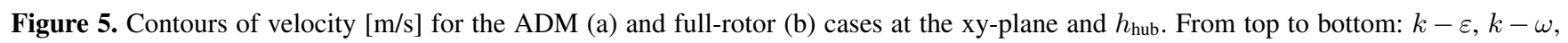
$k-\omega S S T, k-\varepsilon$ Realizable, $k-\varepsilon R N G$. 
Wind Energ. Sci. Discuss., doi:10.5194/wes-2017-6, 2017

Manuscript under review for journal Wind Energ. Sci.

Discussion started: 13 February 2017

(c) Author(s) 2017. CC-BY 3.0 License.

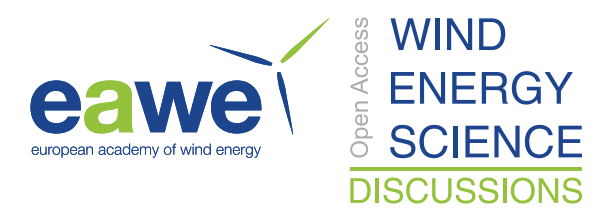

(c) $\underset{B \mathrm{BY}}{\mathrm{B}}$

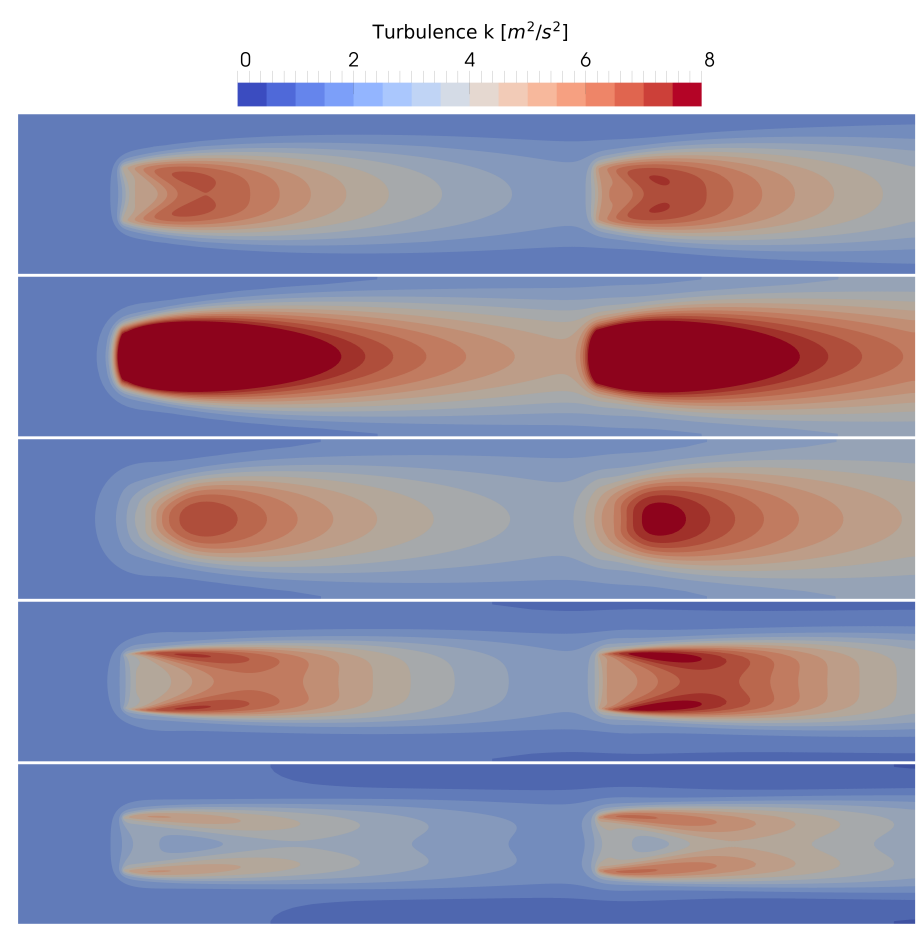

(a)

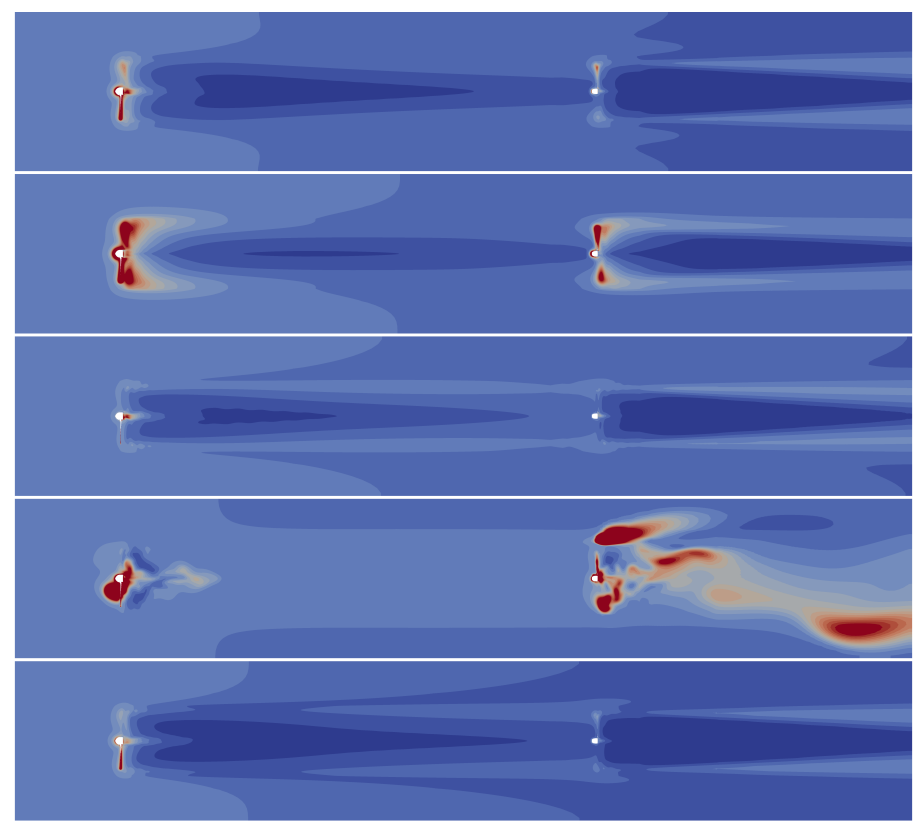

(b)

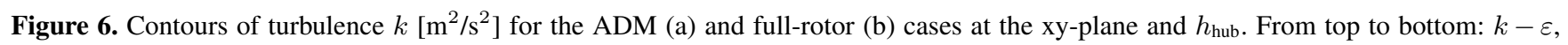
$k-\omega, k-\omega S S T, k-\varepsilon$ Realizable, $k-\varepsilon R N G$. 
Wind Energ. Sci. Discuss., doi:10.5194/wes-2017-6, 2017

Manuscript under review for journal Wind Energ. Sci.

Discussion started: 13 February 2017

(c) Author(s) 2017. CC-BY 3.0 License.

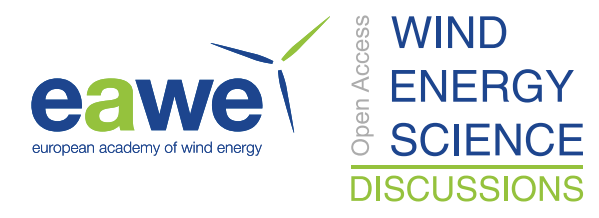

(c) (i)

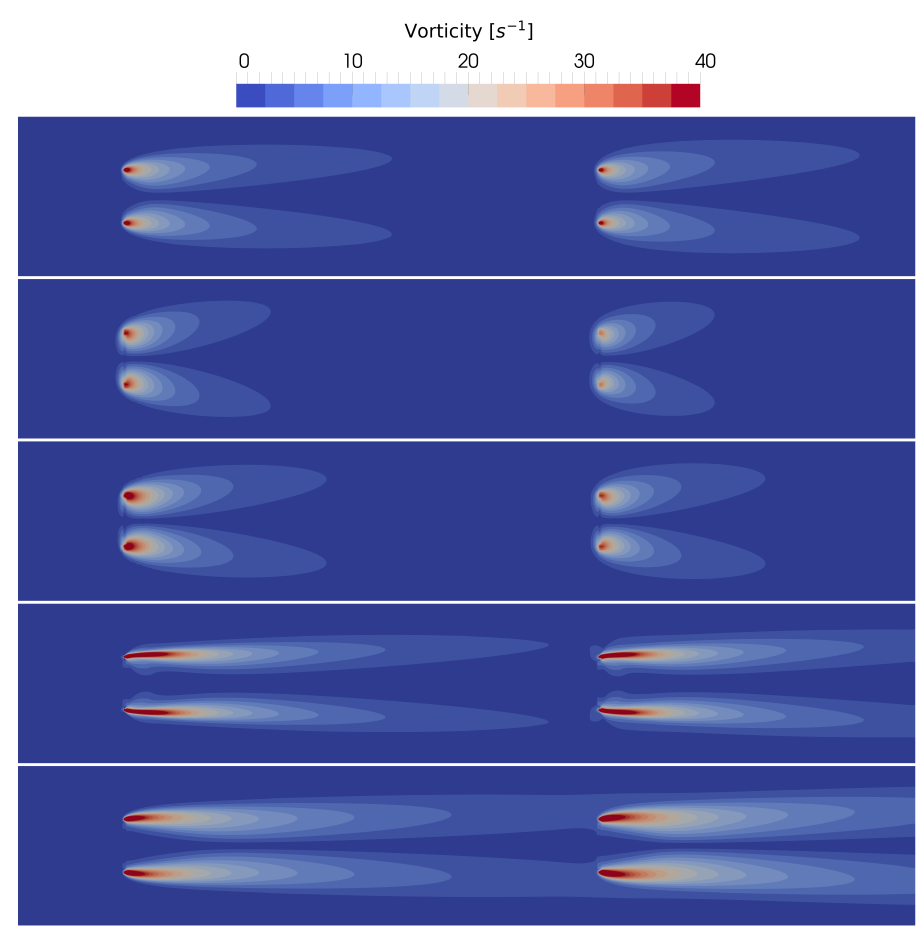

(a)

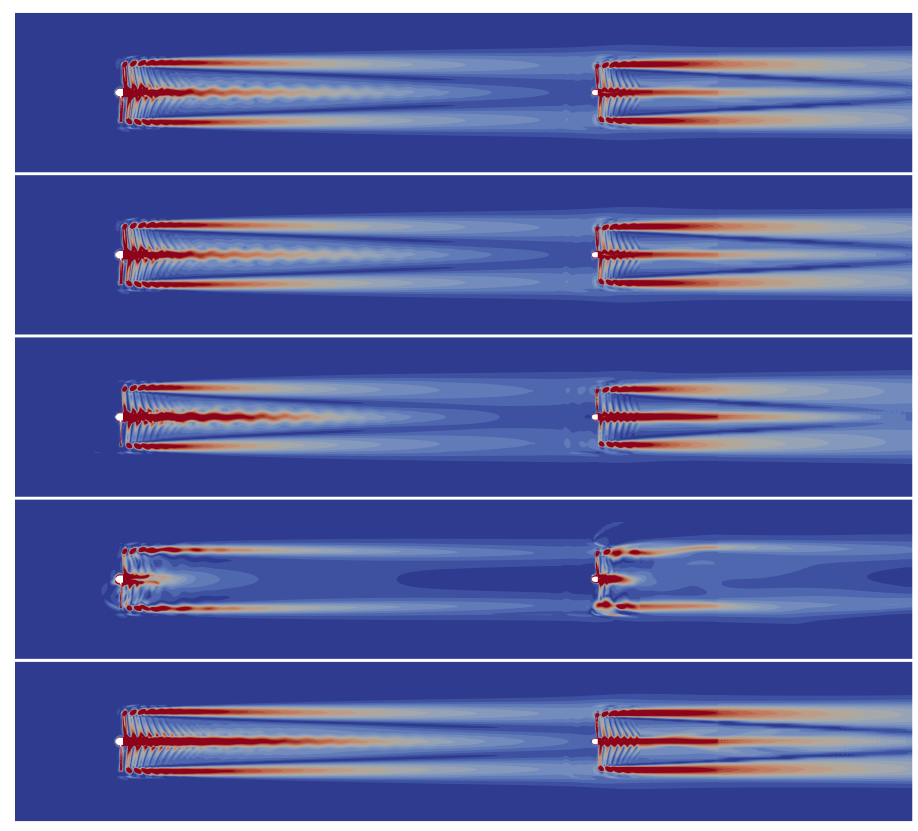

(b)

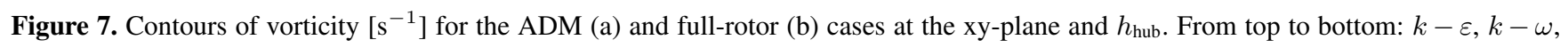
$k-\omega S S T, k-\varepsilon$ Realizable, $k-\varepsilon R N G$. 
Wind Energ. Sci. Discuss., doi:10.5194/wes-2017-6, 2017

Manuscript under review for journal Wind Energ. Sci.

Discussion started: 13 February 2017

(c) Author(s) 2017. CC-BY 3.0 License.

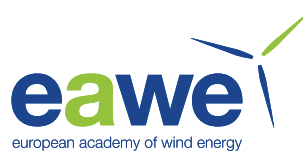

smaller as we are approaching the outlet. The fact that the turbulence intensity decays downstream is known and observed also in several experiments performed in wind tunnels (Sætran and Bartl, 2015). Since the two rotors are identical, and the TSR of the second wind turbine is adjusted to the expected inflow conditions for optimal operation, we expect equal production of turbulence from the two rotors. That is also confirmed by the contours of vorticity (Fig. 7b), despite the small difference at the tip-vortexes of the second wind turbine which operates under the wake effect of the upstream rotor. A further investigation is needed to quantify the impact of the turbulence intensity at the inlet. In our case, we used a given turbulence length scale and a $T I=10 \%$, provided by the experiment. However, those measurements have been performed at the position of the first wind turbine rotor. It is proposed to investigate the turbulence decay under the absence of rotors, at the position of the first wind turbine.

From the velocity contour of the $k-\varepsilon$ Realizable model, a wake meandering is observed at the second wind turbine. This result is not expected in steady state RANS simulations and it is verified as unphysical also by the contour of TKE (Fig. 6) respectively. Therefore, this case is considered unreliable.

\subsection{Comparison against measurements}

Velocity profiles in the wake of the upstream wind turbine rotor are compared with measurements along three horizontal lines at the hub height $\left(h_{\text {hub }}=0.827 \mathrm{~m}\right.$ ), covering an horizontal span width from $z=-0.944 \mathrm{~m}$ to $z=0.944 \mathrm{~m}$. The three horizontal lines L1, L2, L3 are located 2.77D (near), 5.18D (mid) and 8.5D (far wake) downstream of the first wind turbine rotor respectively. Plots of normalized velocity $U^{*}=U_{\text {wake }} / U_{\text {ref }}$ over the rotor's radial distance $(z / R)$ are compared against the BT4 experimental data (Fig. 8, 9).

The correct implementation of the ADM is also validated from the symmetrical U-shaped velocity profile that was expected at the wake region and over horizontal lines at $h_{\text {hub }}$ if a uniform momentum sink of constant thrust is applied (Rados et al., 2012; Mikkelsen, 2003). The plots of normalized velocity (Fig. 8) verify that behaviour for all the turbulence models.

The ADM under-estimates the velocity deficit at all the wake regions downstream for most turbulence models, except from the $k-\varepsilon R N G$ which shows a superb agreement with the measurements (Fig. 8). Nevertheless, as already discussed in section 5.1, results of the ADM are very sensitive to the choice of turbulence model. Quantitatively, over the line L1 at the near wake, the maximum relative difference between the $k-\omega$ and $k-\varepsilon$ turbulence models is $4.046 \mathrm{~m} / \mathrm{s}$ (equal to a relative difference of 0.352 in normalized velocities). The relative difference between the turbulence models decreases as we move further downstream. At the mid wake over line L2, the relative difference is $2.635 \mathrm{~m} / \mathrm{s}$ and at the far wake, over line L3, $1.653 \mathrm{~m} / \mathrm{s}$.

The full wind turbine rotor simulations predict more accurately the near wake, capturing also the shape of the velocity deficit (Fig. 9). At the mid wake, the $k-\varepsilon$ and the $k-\varepsilon R N G$ maintain the "W-shaped" horizontal velocity profile, whereas the other models are in better agreement with the measurements. In the far wake region, over line L3, all the models fail to predict correctly the velocity deficit and overestimate it. The $k-\varepsilon$ Realizable turbulence model shows excellent agreement at the mid and far wake regions, but as already discussed in section 5.1, it is unreliable. Preliminary results suggest that the impact of tower will increase the TKE at wake, resulting to a better agreement at the far region. A further study on the performance of 
Wind Energ. Sci. Discuss., doi:10.5194/wes-2017-6, 2017

Manuscript under review for journal Wind Energ. Sci.

Discussion started: 13 February 2017

(c) Author(s) 2017. CC-BY 3.0 License.

\section{Actuator Disk}
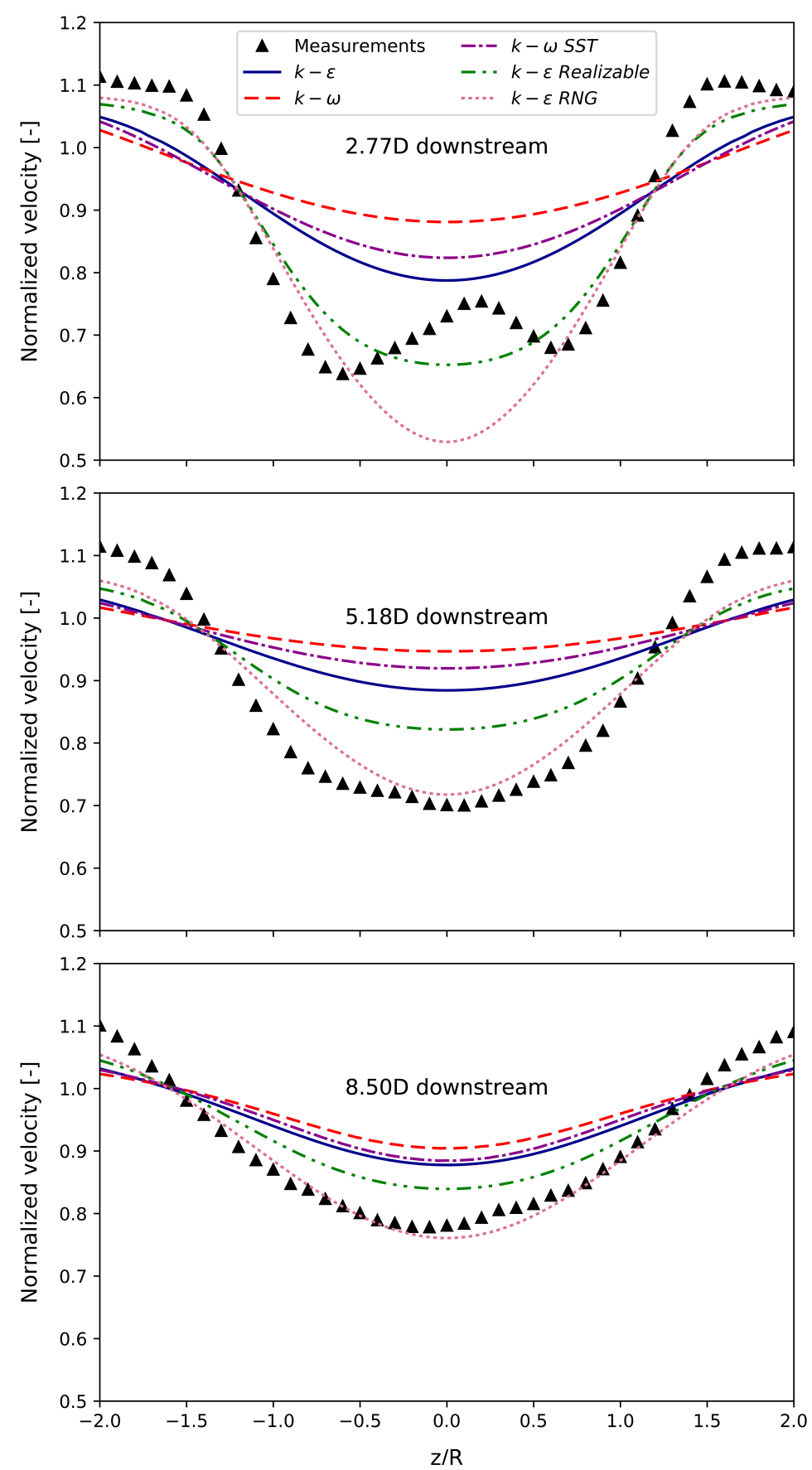

Figure 8. Results of actuator disk model CFD simulations, using several turbulence models against measurements. From top to bottom: line L1, L2 and L3 respectively. 
Wind Energ. Sci. Discuss., doi:10.5194/wes-2017-6, 2017

Manuscript under review for journal Wind Energ. Sci.

Discussion started: 13 February 2017

(c) Author(s) 2017. CC-BY 3.0 License.

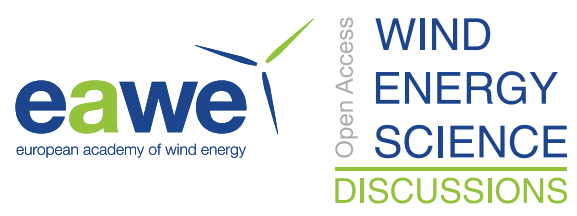

(c) (1)

\section{Full Rotor}
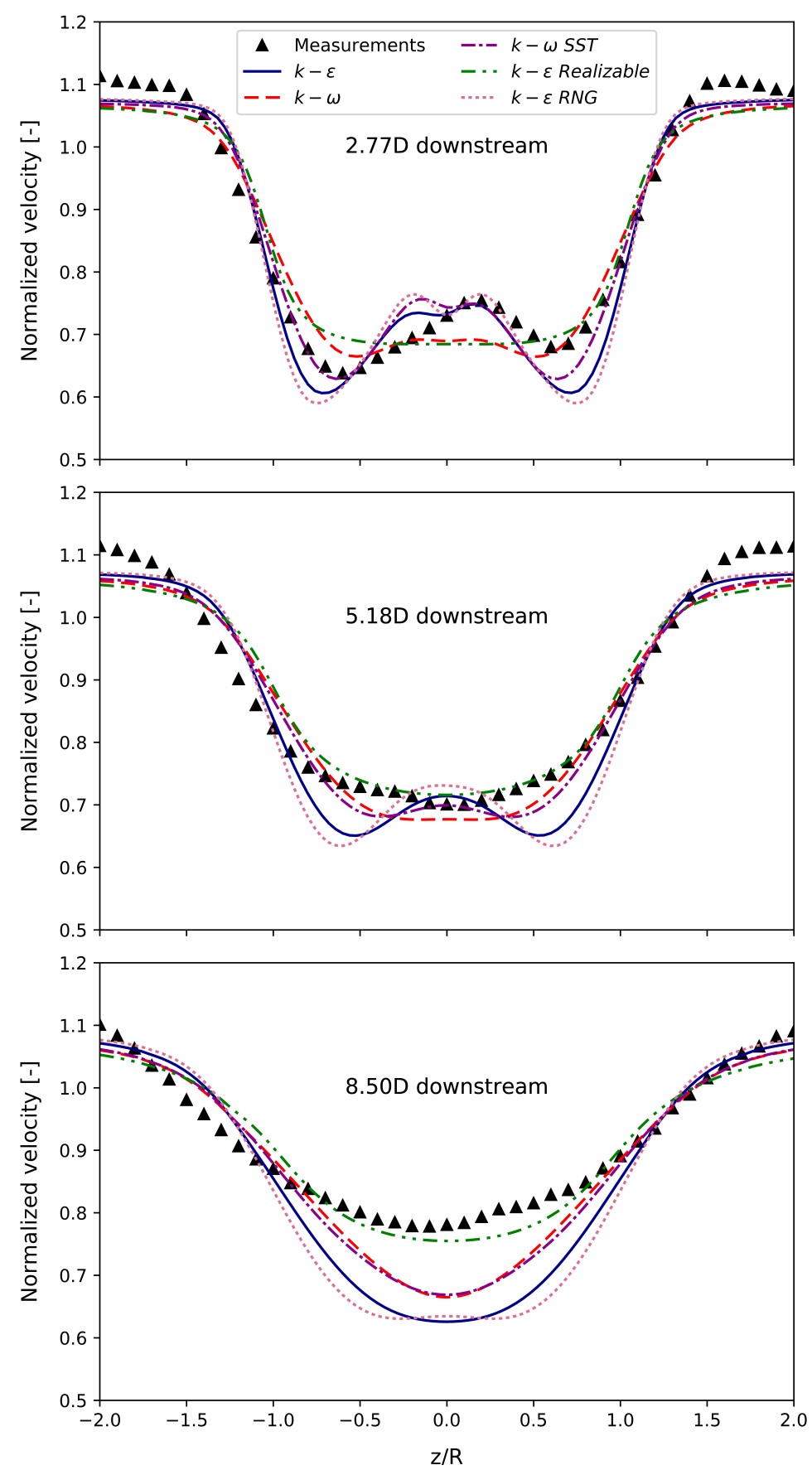

Figure 9. Results of full-rotor CFD simulations, using several turbulence models against measurements. From top to bottom: line L1, L2 and L3 respectively. 
Wind Energ. Sci. Discuss., doi:10.5194/wes-2017-6, 2017

Manuscript under review for journal Wind Energ. Sci.

Discussion started: 13 February 2017

(c) Author(s) 2017. CC-BY 3.0 License.

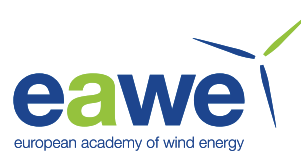

different turbulence models including the nacelle and tower will be performed by the authors in the future. It is concluded that for full-rotor CFD approach, the group of $k-\omega$ turbulence predicts the velocity deficit more accurately, with the $k-\omega S S T$ showing slightly better performance.

\section{Conclusions}

The wake expansion of a wind turbine was investigated under controlled conditions of a wind tunnel, using different CFD modelling approaches. The OpenFOAM open-source platform was used, with the multiple reference frame (MRF) utility (for the case of the full wind turbine rotor) and the standard actuator disk model to solve the 3-dimensional, incompressible, steady state RANS. Five RANS turbulence models have been tested on both cases (full rotor and actuator disk). The models were compared with experimental data at three downstream positions over horizontal lines at hub height.

On average, the actuator disk models under-predict the velocity deficit in the wake. The under-prediction of the far wake by ADM was observed also by other studies (Rados et al., 2012; Sanderse et al., 2011; Vafiadis et al., 2013; Crasto et al., 2012; Prospathopoulos et al., 2011). Especially for the downstream distance of five diameters, which is of high interest since it is commonly used by industry as a separation distance in wind farms, results show that there is a failure to capture accurately the velocity deficit with the standard actuator disk model for most turbulence models. However, good results are obtained with an appropriate turbulence model: the $k-\varepsilon R N G$ shows excellent agreement in the mid and far wake.

Full-rotor simulations show very good agreement in the near and mid wake. On the other hand, they all over-estimate the velocity deficit in the far wake, which is related to the severe under-estimation of the turbulence intensity by the full-rotor simulations. Preliminary calculations that we have performed, suggest that including the tower and nacelle might lead to better prediction of the far wake. This topic needs further investigation.

Acknowledgements. This work has been funded by INNOVIRIS, the Brussels Institute for the promotion of scientific research and innovation,

5 in the framework of the DOCTIRIS program and under the research project: "Non-deterministic advanced CFD modelling of wind turbine wakes and their interaction with applications to wind farms including complex terrain effects".

The authors acknowledge the Norwegian Technical National University (NTNU) for providing the experimental data of Blind Test 4 and professors Lars Roar Sætran and Per-Åge Krogstad for their support. 
Wind Energ. Sci. Discuss., doi:10.5194/wes-2017-6, 2017

Manuscript under review for journal Wind Energ. Sci.

Discussion started: 13 February 2017

(c) Author(s) 2017. CC-BY 3.0 License.

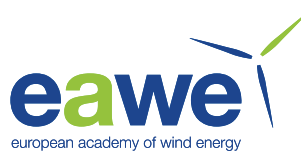

\section{References}

Ainslie, J. F.: Calculating the flow field in the wake of wind turbines, Journal of Wind Engineering and Industrial Aerodynamics, 27, 213$-224,1988$.

Barthelmie, R. J., Rathmann, O., Frandsen, S. T., Hansen, K. S., Politis, E. S., Prospathopoulos, J. M., Rados, K. G., Cabezón, D., Schlez, W., Phillips, J., Neubert, A., Schepers, J. G., and van der Pijl, S. P.: Modelling and measurements of wakes in large wind farms, Journal of Physics: Conference Series, 75, 012 049, doi:10.1088/1742-6596/75/1/012049, 2007.

Crasto, G., Gravdahl, A. R., Castellani, F., and Piccioni, E.: Wake modeling with the actuator Disc concept, Energy Procedia, 24, 385-392, doi:10.1016/j.egypro.2012.06.122, 2012.

Hellsten, A.: Some improvements in Menter's k-omega SST turbulence model, 29th AIAA, Fluid Dynamics Conference, pp. 1-11, doi:10.2514/6.1998-2554, 1998.

Jensen, N. O.: A note on wind turbine interaction, Ris $\varnothing-M-2411$, Risoe National Laboratory, Roskilde, Denmark, p. 16 pp., 1983.

Katic, I., Højstrup, J., and Jensen, N. O.: A simple model for cluster efficiency, Proceedings: European Wind Energy Association Conference and Exhibition, Rome, Italy, pp. 407-409, 1986.

Larsen, G. C., Højstrup, J., and Madsen, H. A.: Wind field in wakes, Proceedings: European Wind Energy Conference and Exhibition 1996, Gothenberg, Sweden, pp. 764-768, 1996.

Larsen, G. C., Carlen, I., and Schepers, J. G.: Fatigue life consumption in wake operation, Proceedings: European Wind Energy Conference and Exhibition 1998, Dublin, Ireland, Irish Wind Energy Association, pp. 605-610, 1998.

Larsen, G. C., Madsen, H. A., and Sørensen, N. N.: Mean wake deficit in the near field, Proceedings: European Wind Energy Conference 2003, Madrid, Spain, EWEA, 2003.

Launder, B. E. and Spalding, D. B.: The numerical computation of turbulent flows, Computer Methods in Applied Mechanics and Engineering, 3, 269-289, doi:10.1016/0045-7825(74)90029-2, 1974.

30 Launder, B. E., Morse, A., Rodi, W., and Spalding, D. B.: Prediction of free shear flows: A comparison of the performance of six turbulence models, in: NASA. Langley Res. Center Free Turbulent Shear Flows, vol. 1, pp. 361-426, 1973.

Magnusson, M., Rados, K. G., and Voutsinas, S. G.: A study of the flow down stream of a wind turbine using measurements and simulations, Wind Engineering, 20, 389—403, 1996.

Markatos, N. C.: The mathematical modelling of turbulent flows, Applied Mathematical Modelling, 10, 190-220, 1986.

Menter, F. R.: Two-Equation Eddy-Viscosity Turbulence Models for Engineering Applications, AIAA, 32, 1598-1605, 1994.

Menter, F. R., Kuntz, M., and Langtry, R.: Ten Years of Industrial Experience with the SST Turbulence Model, Turbulence Heat and Mass Transfer 4, 4, 625-632, doi:10.4028/www.scientific.net/AMR.576.60, 2003.

Mikkelsen, R.: Actuator disc methods applied to wind turbines, Ph.d thesis, Technical University of Denmark, 2003.

OpenFOAM: openfoam.org, www.openfoam.org, 2016.

Patankar, S. V. and Spalding, D. B.: A calculation procedure for heat, mass and momentum transfer in three-dimensional parabolic flows, International Journal of Heat and Mass Transfer, 15, 1787-1806, 1972.

5 Prospathopoulos, J. M., Politis, E. S., Rados, K. G., and Chaviaropoulos, P. K.: Evaluation of the effects of turbulence model enhancements on wind turbine wake predictions, Wind Energy, 14, 285-300, doi:10.1002/we.419, 2011.

Rados, K. G., Larsen, G., Barthelmie, R., Schlez, W., Lange, B., Schepers, J. G., Hegberg, T., and Magnusson, M.: Comparison of wake models with data for offshore windfarms, Wind Engineering, 25, 271—280, 2002. 
Wind Energ. Sci. Discuss., doi:10.5194/wes-2017-6, 2017

Manuscript under review for journal Wind Energ. Sci.

Discussion started: 13 February 2017

(c) Author(s) 2017. CC-BY 3.0 License.

(c) (i)

Rados, K. G., Mosfilis, S., Stergiannis, N., Tourlidakis, A., Caralis, G., and Zervos, A.: CFD modeling approaches of wind turbine single and multiple wakes, in: European Wind Energy Conference and Exhibition 2012, EWEC 2012, vol. 3, pp. 1842-1849, 2012.

Sætran, L. and Bartl, J.: Invitation to the 2015 "Blind test 4" Workshop Combined power output of two in-line turbines at different inflow conditions, 2015.

Sanderse, B., Pijl, S. P., and Koren, B.: Review of computational fluid dynamics for wind turbine wake aerodynamics, Wind Energy, 14, 799-819, doi:10.1002/we.458, 2011.

15 Shih, T., Liou, W., Shabbir, A., Yang, Z., and Zhu, J.: A New k-epsilon Eddy Viscosity Model for High Reynolds Number Turbulent Flows, Computers and Fluids, 10, 227-238, 1995.

Vafiadis, K., Stergiannis, N., Tourlidakis, A., and Rados, K. G.: Computational investigation of horizontal axis wind turbine wake, in:

European Wind Energy Conference and Exhibition, EWEC 2013, vol. 3, pp. 1692-1700, 2013.

Vermeer, L. J., Sørensen, J. N., and Crespo, A.: Wind turbine wake aerodynamics, Progress in Aerospace Sciences, 39, 467-510, doi:10.1016/S0376-0421(03)00078-2, 2003.

Wilcox, D. C.: Reassessment of the Scale-Determining Equation for Advanced Turbulence Models, AIAA Journal, 26, $1299-1310,1988$.

Wilcox, D. C.: Turbulence modeling for CFD, vol. 93, DCW Industries, 1st edition edn., doi:0963605151, 1993.

325 Wilcox, D. C.: Formulation of the k-w Turbulence Model Revisited, AIAA Journal, 46, 2823-2838, doi:10.2514/1.36541, 2008.

Yakhot, V., Orszag, S. A., Thangam, S., Gatski, T. B., and Speziale, C. G.: Development of Turbulence Models for Shear Flow by a Double Expansion Technique, Physics of Fluids, 4, 1510-1520, 1992. 